\title{
Paid maternity leave extension and exclusive breastfeeding practice: evidence from Brunei
}

\author{
Mohammed M. Alhaji', Sharbawi Roslin², Adrian Kay ${ }^{3,4}$, Nik A.A. Tuah ${ }^{1,5, *}$
}

\section{Abstract}

Background: Exclusive breastfeeding (EBF) of infants in their first 6 months postpartum is beneficial. However, maternal employment and short maternity leave impede EBF practice. In 2011, Brunei implemented a new Maternity Leave Regulation to extend paid maternity leave.

Objectives: To compare the prevalence of EBF between employed and nonworking mothers in Brunei, before and after extending paid maternity leave, to determine its effect on EBF and to determine the effects of maternal and infant sociodemographic characteristics.

Methods: Cross-sectional review of feeding records for infants born in $2010(\mathrm{n}=6412,85.5 \%$ all live births $)$ and 2013 $(\mathrm{n}=6680,85.7 \%)$.

Results: EBF prevalence at 6 months postpartum increased from $29 \%$ in 2010 to $41 \%$ in 2013. EBF prevalence was higher among multiparous mothers $(P<0.001)$, mothers of Malay ethnicity $(P<0.05)$, and mothers of girls $(P<0.01$ only in 2013) in both years. EBF prevalence among government-employed mothers $(81.0 \%, 67.7 \%$, and $57.8 \%)$ was greater than it was among nonworking mothers $(79.1 \%, 66.3 \%$, and $56.9 \%)$ by $1.9,1.4$, and 0.9 percentage points, respectively, during the first 3 months of active paid maternity leave in 2013. Mothers employed in the government and private sectors showed greater increases in the practice of EBF (15.5 and 10.8 percentage points respectively) than nonworking mothers (8.8 percentage points) from 2010 to 2013.

Conclusions: EBF prevalence increased after extending paid maternity leave, with the greatest increases seen among employed mothers. Maternal ethnicity, parity, and the sex of the infant were also correlated with EBF.

Keywords: breastfeeding, child health and nutrition, early life, health policies, maternal, parity

As recommended by the World Health Organization (WHO), the practice of feeding the newborn with only breastmilk (and prescribed medications when indicated) in their first 6 months of life, otherwise termed exclusive breastfeeding (EBF), has been shown to offer benefits, such as improved cognitive and sensory development, decreased risks from childhood-related killer diseases in the child and reduced risks of ovarian and breast cancers in the mother [1-4].

*Correspondence to: Nik A.A. Tuah, PAP Rashidah Sa'adatul Bolkiah Institute of Health Sciences, Universiti Brunei Darussalam, Jalan Tungku Link Gadong, BE1410, Brunei, e-mail: anni.mohamad@ubd.edu.bn

'Pengiran Anak Puteri Rashidah Sa'adatul Bolkiah Institute of Health Sciences, Universiti Brunei Darussalam, BE1410, Brunei ${ }^{2}$ Maternal and Child Health Services, Ministry of Health, Brunei-Muara, BB3910, Brunei

${ }^{3}$ Institute of Policy Studies, Universiti Brunei Darussalam, BE1410, Brunei

${ }^{4}$ Crawford School of Public Policy, The Australian National University, Canberra, ACT 2600, Australia

${ }^{5}$ Department of Primary Care and Public Health, Imperial College London, London SW7 2AZ, United Kingdom

D Open Access. ๑ 2017 Mohammed M. Alhaji et al., published by Sciendo. (c) BY-NC-ND This work is licensed under the Creative Commons Attribution NonCommercial-NoDerivatives 4.0 License. 
Other benefits associated with EBF have also been documented from a spectrum of social and economic perspectives. An economic review suggested that about US\$3.6 billion could be saved from treatment expenses for 3 childhoodrelated diseases (gastroenteritis, otitis media, and necrotizing enterocolitis) if the EBF levels in the United States of America (USA) were increased from $29 \%$ to $50 \%$ at 6 months postpartum, and from $64 \%$ to $75 \%$ for mothers in-hospital as recommended by the U.S. Surgeon General [5].

Despite the benefits of EBF, globally, only two-fifths of infants are exclusively breastfed in the first 6 months of their lives [6]. Factors such as maternal employment and short maternity leave, among many others, have been found to play significant roles in the poor uptake of EBF by mothers [7-10]. Studies conducted on breastfeeding practice among new mothers in the United Kingdom (UK) [11] and USA [7] found a significant association between longer maternal leave and longer breastfeeding duration.

Effective from January 2011, Brunei implemented a new Maternity Leave Regulation 2011, which extended the duration of $100 \%$ paid maternity leave (PML) from 8 weeks (or 56 days) to 15 weeks (or 105 days) for civil servants (public sector or government employees) and 13 weeks (or 91 days) for private sector employees, consistent with recommendations by the International Labour Organization [12].

The present study aimed to determine the prevalence of EBF among employed and nonworking mothers, before and after implementing the Brunei Maternity Leave Regulation 2011, to determine the effect of PML on EBF prevalence, and to determine the effect of sociodemographic variables such as maternal race, area of residence, and the sex of the infant on EBF prevalence.

\section{Methods}

The study protocol was approved by the Medical and Health Research Ethics Committee, Ministry of Health, Negara Brunei Darussalam (approval reference MHREC/MOH/2014/7(6)). All records obtained from the databases of the Mother and Child Health $(\mathrm{MCH})$ clinics were entered anonymously (i.e., address and names of the parents were not considered), and all variables were coded during entry into the statistical software, thereby making it impossible to trace any variable to a specific person.

\section{Study design and sampling}

The present study is a quantitative retrospective cross-sectional observational review of national infant feeding records for
2 years (2010 and 2013), collected from the $22 \mathrm{MCH}$ clinics in Brunei. In the $\mathrm{MCH}$ clinics, all infants are followed up every month for the first 6 months of their life. Apart from the assessment of their development, the infant's feeding status is also recorded. For this study, we collected the EBF status records of infants born in $2010(n=6412)$ and $2013(n=6680)$, representing $85.5 \%$ all live births in 2010 and $85.7 \%$ of those in 2013. Incomplete or unavailable records of EBF status ( $n=$ 928 in 2010 and $\mathrm{n}=955$ in 2013) were not included in this study (Figure 1).

\section{Definition of variables}

EBF was defined as feeding the infant exclusively with breastmilk, and prescribed medications when indicated, for the first 6 months of the infant's life postpartum. Mothers with previous childbirth(s) are referred to as multiparous mothers, whereas a first-time mother is referred to as a primiparous mother.

A full 1-month or 30-day period when new mothers in employment were on leave from work with $100 \%$ salary entitlement is termed active PML. When the leave was only applicable for 12 days, as in 2010 before the new Maternity Leave Regulation 2011, it is termed $1 / 2$ active PML. Inactive PML is when the leave is exhausted and the mother has resumed working.

\section{Statistical analyses}

EBF prevalence is described using frequency (\%) and sum. A $\chi^{2}$ test of independence was used to assess the level of difference between comparable groups. Logistic regression was used to determine the odds ratios of the covariates for the likelihood of practicing EBF at 6 months of infant age. The Hosmer-and-Lemeshow goodness-of-fit test was used to assess the model in terms of fitness of the data. All differences at $P<0.05$ were considered significant. Data were analyzed using IBM SPSS Statistics for Windows (version 22.0).

\section{Results}

\section{Sociodemographic profile of the sample population}

The majority of the sample in this study consisted of nonworking mothers (43.0\% in 2010 and $45.1 \%$ in 2013), followed by mothers employed by the government (37.7\% in 2010 and 38.1\% in 2013) and in the private sector (19.3\% in 2010 and $16.8 \%$ in 2013). The majority of the mothers were Bruneian citizens 


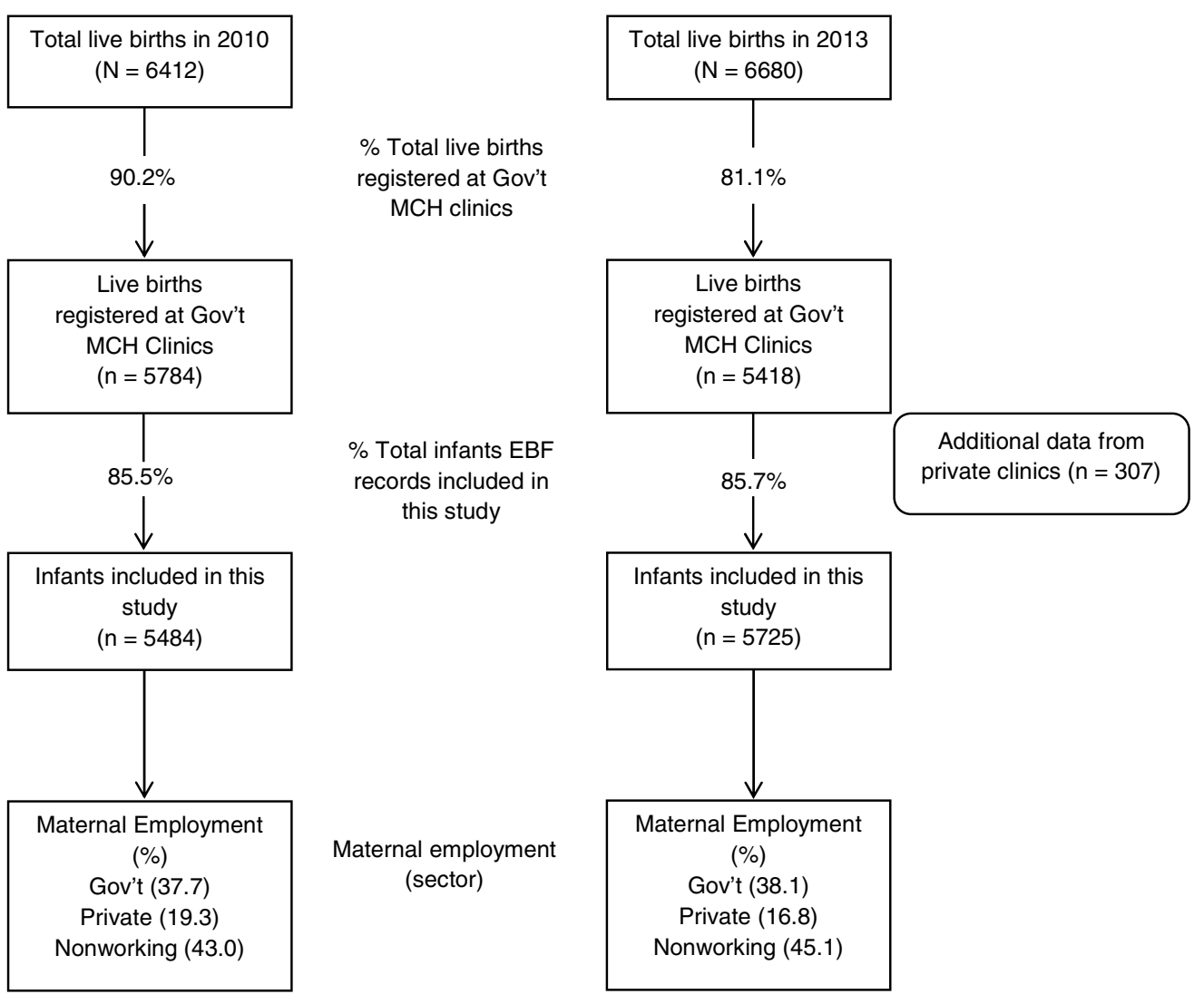

Figure 1. Study data flowchart. Gov't MCH Clinics, government mother and child health clinics.

(89.3\% in 2010 , and $92.1 \%$ in 2013$)$, multigravidas (70.1\% and $68.7 \%$ ), Malay $(85.9 \%$ and $88.3 \%$ ), and residents of BruneiMuara district (71.9\% and $71.1 \%$ in 2010 and 2013, respectively). The sex of the infants was nearly equally distributed for both years (51\% male, 49\% female) as shown in Figure 1 and Table 1.

\section{EBF prevalence at 1-6 months of infant age}

The prevalence of EBF at 6 months of infant age was $29 \%$ (71\% at 1 month of infant age) in 2010, and $41 \%$ (79\% at 1 month of infant age) in 2013. EBF practice improved significantly (from 2010 to 2013) by 7 percentage points at 1 month of infant age and 12 percentage points at 6 months of infant age. The prevalence of EBF in 2013 was significantly higher than the prevalence of EBF in 2010 for the first 6 months of infant age $(P<0.001)$ (Table 2).

\section{Factors associated with EBF}

Multiparous mothers (30.7\% in 2010, and $43.0 \%$ in 2013) practiced EBF more than primiparous women did $(23.9 \%$ in 2010 , and $37.2 \%$ in 2013), and the difference was highly
Table 1. Demographic profile of new mothers and infants

\begin{tabular}{|c|c|c|}
\hline \multirow{2}{*}{ Variable } & \multicolumn{2}{|c|}{ n (\%) } \\
\hline & 2010 & 2013 \\
\hline \multicolumn{3}{|c|}{ Maternal employment } \\
\hline Government & $2066(37.7)$ & $2182(38.1)$ \\
\hline Private sector & $1056(19.3)$ & $962(16.8)$ \\
\hline Nonworking & $2362(43.0)$ & $2581(45.1)$ \\
\hline \multicolumn{3}{|c|}{ Maternal citizenship } \\
\hline Bruneian & $4899(89.3)$ & $5270(92.1)$ \\
\hline Non-Bruneian & $585(10.7)$ & 455 (7.9) \\
\hline \multicolumn{3}{|l|}{ Parity } \\
\hline Primiparous & $1641(29.9)$ & $1794(31.3)$ \\
\hline Multiparous & $3843(70.1)$ & $3931(68.7)$ \\
\hline \multicolumn{3}{|l|}{ Infant's sex } \\
\hline Male & $2804(51.1)$ & $2917(51.0)$ \\
\hline Female & $2680(48.9)$ & $2808(49.0)$ \\
\hline \multicolumn{3}{|c|}{ Maternal ethnicity } \\
\hline Malay & $4710(85.9)$ & $5058(88.3)$ \\
\hline Chinese & $337(6.1)$ & $309(5.4)$ \\
\hline Others & $437(8.0)$ & $358(6.3)$ \\
\hline \multicolumn{3}{|c|}{ Maternal district of residence } \\
\hline Brunei-Muara & 3947 (71.9) & $4070(71.1)$ \\
\hline Tutong & $648(11.8)$ & $630(11.0)$ \\
\hline Kuala Belait & 749 (13.7) & $895(15.6)$ \\
\hline Temburong & $140(2.6)$ & $130(2.3)$ \\
\hline
\end{tabular}


Table 2. The prevalence of exclusive breastfeeding from 1 month to 6 months of infant age in 2010 and 2013

\begin{tabular}{lrrrrr}
\hline $\begin{array}{l}\text { Infant age } \\
\text { (months) }\end{array}$ & \multicolumn{2}{c}{$\%$ (95\% Cl) } & P' & $\begin{array}{r}\text { Percentage } \\
\text { point increase }\end{array}$ \\
\cline { 2 - 4 } & $\mathbf{2 0 1 0}$ & $\mathbf{2 0 1 3}$ & & 7 \\
1 & $71(70$ to 72$)$ & $78(77$ to 79$)$ & $<0.001$ & 13 \\
3 & $51(50$ to 53$)$ & $64(63$ to 66$)$ & $<0.001$ & 14 \\
4 & $41(40$ to 42$)$ & $55(53$ to 56$)$ & $<0.001$ & 14 \\
5 & $34(33$ to 35$)$ & $48(46$ to 49$)$ & $<0.001$ & 12 \\
6 & $29(27$ to 30$)$ & $42(41$ to 43$)$ & $<0.001$ & 12 \\
\hline
\end{tabular}

${ }^{t} \chi^{2}$ test of independence; $\mathrm{Cl}$, confidence interval.

significant for both years $(P<0.001)$. While female infants were more likely to be exclusively breastfed, the difference in 2013 (43.3\% female versus 39.2\% male) was significant $(P=0.002)$, whereas the difference in 2010 (29.2\% female versus $28.1 \%$ male) was not $(P=0.39)$ (Table 3 ).

Maternal ethnicity also showed an important correlation with the practice of EBF. Mothers of Malay ethnicity $(29.5 \%$ in 2010 , and $41.6 \%$ in 2013) showed greater practice of EBF than mothers of Chinese ethnicity $(19.0 \%$ in 2010 , and $32.5 \%$ in 2013$)$ and the combined group of a minority race $(27.2 \%$ in 2010 , and $42.0 \%$ in $2013 ; P<0.05$ for both years). We found no influence of maternal district of residence on the practice of EBF ( $P>0.05$ for both years) (Table 3).

In a multiple logistic regression (MLR) model, the odds of primiparous mothers practicing EBF were lower than the odds for multiparous mothers practicing $\mathrm{EBF}$ at 6 months of infant age in both years (2010 and 2013), but the odds improved slightly from being 26\% less likely to practice EBF in 2010 (adjusted odds ratio [AoR]: $0.74 ; 95 \%$ CI 0.64 to $0.84 ; P<0.001)$ to $20 \%$ less likely to practice EBF (AoR $0.80 ; 95 \%$ CI 0.71 to $0.90 ; P$ $<0.001$ ) than multiparous mothers. Maternal ethnicity was a significantly different variable in the MLR model in 2010 (and not in 2013), but the odds of EBF at 6 months of infant age were not significantly different between the 3 ethnic groups (Malay, Chinese, and others). Male infants were 15 percentage points less likely (AoR 0.85; 95\% CI 0.77 to $0.95 ; P=0.04$ ) to be exclusively breastfed than female infants in 2013 (Table 4).

\section{Maternal employment and EBF practice}

EBF among mothers employed by the government at 1 month of infant age increased by 9 percentage points, from $72.0 \%$ (2010) to $81.0 \%$ (2013), and at 6 months of infant age by 15.5 percentage points, from $24.9 \%$ (2010) to $40.4 \%$ (2013). The greatest increase in EBF prevalence (18.5 percentage points) among all groups was seen among mothers employed by the
Table 3. Sociodemographic variables associated with exclusive breastfeeding at 6 months of infant age

\begin{tabular}{|c|c|c|c|c|c|c|}
\hline \multirow{2}{*}{ Variable } & \multicolumn{3}{|c|}{2010} & \multicolumn{3}{|c|}{2013} \\
\hline & $\mathbf{n}$ & EBF, n (\%) & $\boldsymbol{P}^{\dagger}$ & $\mathbf{n}$ & EBF, n (\%) & $P^{\dagger}$ \\
\hline \multicolumn{7}{|l|}{ Parity } \\
\hline Primiparous & 1641 & $393(23.9)$ & $<0.001$ & 1721 & $640(37.2)$ & $<0.001$ \\
\hline Multiparous & 3843 & $1178(30.7)$ & & 3843 & $1654(43.0)$ & \\
\hline \multicolumn{7}{|l|}{ Infant's sex } \\
\hline Male & 2804 & $789(28.1)$ & 0.39 & 2829 & 1109 (39.2) & 0.002 \\
\hline Female & 2680 & 782 (29.2) & & 2735 & 1185 (43.3) & \\
\hline \multicolumn{7}{|l|}{ Mother's } \\
\hline \multicolumn{7}{|l|}{ ethnicity } \\
\hline Malay & 4710 & $1388(29.5)$ & $<0.001$ & 5024 & 2092 (41.6) & 0.012 \\
\hline Chinese & 337 & $64(19.0)$ & & 265 & $86(32.5)$ & \\
\hline Others $^{\ddagger}$ & 437 & $119(27.2)$ & & 275 & $116(42.2)$ & \\
\hline \multicolumn{7}{|l|}{$\begin{array}{l}\text { District of } \\
\text { residence }\end{array}$} \\
\hline Brunei-Muara & 3947 & $1093(27.7)$ & 0.063 & 3923 & 1594 (40.6) & 0.50 \\
\hline Tutong & 648 & $210(32.4)$ & & 630 & $273(43.3)$ & \\
\hline Kuala Belait & 749 & $227(30.4)$ & & 882 & $370(42.0)$ & \\
\hline Temburong & 140 & $41(29.3)$ & & 129 & $57(44.2)$ & \\
\hline
\end{tabular}

${ }^{\dagger} \chi^{2}$ test of independence; ${ }^{\ddagger}$ indigenous groups of Malay ethnicity: Belait, Bisaya, Brunei, Dusun, Kedayan, Murut, and Tutong. EBF, exclusive breastfeeding.

Table 4. Variables associated with exclusive breastfeeding at 6 months of infant age in 2010 and $2013^{+}$

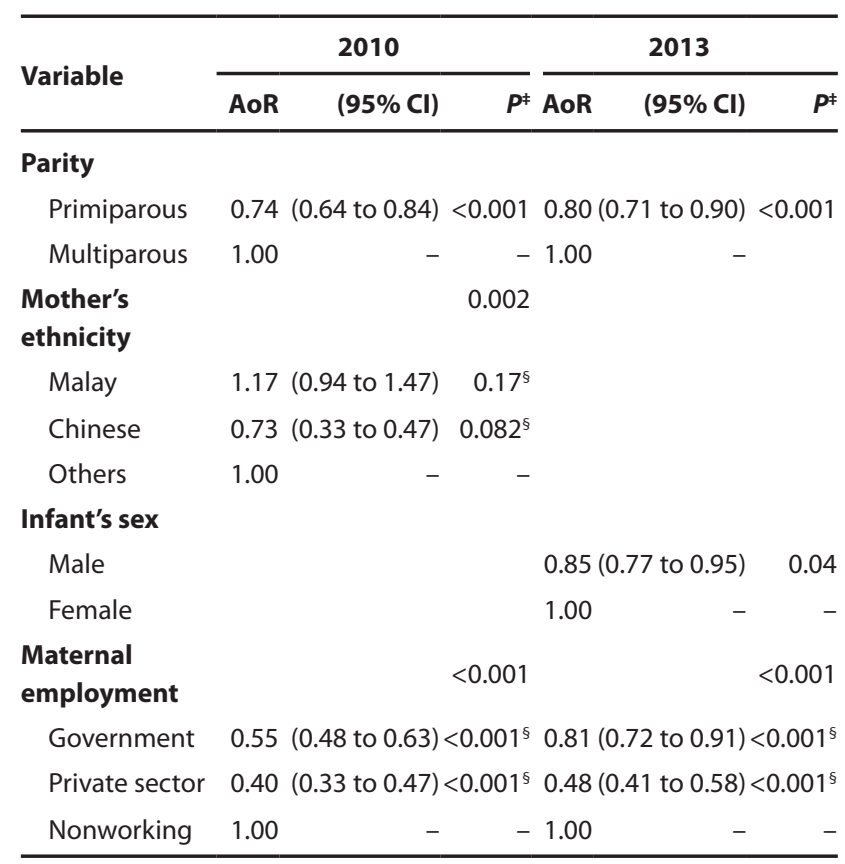

${ }^{\dagger}$ Multiple logistic regression; " ${ }^{\prime}$ likelihood ratio test; ${ }^{5}$ Wald test; AoR, adjusted odds ratio; $\mathrm{Cl}$, confidence interval; Nagelkarke $R^{2}=0.048$ (2010), 0.024 (2013). 
government at 3 months of infant age, from $39.3 \%$ in 2010 to $57.8 \%$ in 2013 . Mothers employed by the government showed greater prevalence of EBF in 2013 than they did in 2010, and the increase was more than that for both nonworking mothers and mothers employed in the private sector (Table 5).

The prevalence of EBF was lower for mothers employed in the private sector than it was for those employed by the government or nonworking mothers in both 2010 and 2013. Nevertheless, mothers employed in the private sector had a greater improvement in EBF prevalence in 2013 (compared with 2010) than nonworking mothers, from 2 months through 6 months of infant age. Ultimately, EBF practice at 6 months of infant age was higher among nonworking mothers $(36.7 \%$ in $2010 ; 45.5 \%$ in 2010) than it was among mothers employed by the government $(24.9 \%$ in $2010 ; 40.4 \%$ in 2012$)$ and those employed in the private sector (17.9\% in 2010; 28.7\%) (Table 5).

To determine the difference in EBF practice during active periods of PML in 2010 (56 days) and 2013 (105 days), we compared the practice of EBF at 1-6 months of infant age between mothers employed by the government and nonworking mothers in 2010 and 2013. Mothers employed in the private sector were excluded from this comparison because their PML was 91 days (from 56 days, pre-Maternity Leave Regulation 2011) and less uniform.

In 2010, the EBF practice at 1-month infant age (PML fully active) between government-employed mothers (72.0\%) and nonworking mothers (72.5\%) was comparable. However, by the second month of infant age (PML terminated in 2010), the difference in EBF practice between government-employed mothers (51.3\%) and nonworking mothers (55.4\%) had widened by $>4$ percentage points. The gap in EBF practice kept widening until 6 months of infant age, when the difference in EBF practice between government-employed mothers $(24.9 \%)$ and nonworking mothers $(36.7 \%)$ was the largest, at 11.8 percentage point difference, as shown in Table 6.

However, in 2013, for the first 3 months of infant age (active period of PML), EBF prevalence for mothers working in the government sector $(81.0 \%, 67.7 \%$, and $57.8 \%$, respectively, for each consecutive month) was greater than it was for nonworking mothers $(79.1 \%, 66.3 \%$, and $56.9 \%$ respectively) by $1.9,1.4$, and 0.9 percentage points, respectively, for each consecutive month. However, by 4 months of infant age (PML inactive), the EBF prevalence for nonworking mothers $(51.5 \%)$ was higher than that for government-employed

Table 5. Change in the trend for exclusive breastfeeding according to employment sector in 2010 and 2013

\begin{tabular}{|c|c|c|c|c|c|c|c|c|c|}
\hline \multirow{2}{*}{$\begin{array}{l}\text { Infant age } \\
\text { (months) }\end{array}$} & \multicolumn{3}{|c|}{ Government sector (\%) } & \multicolumn{3}{|c|}{ Nonworking (full-time housewives) (\%) } & \multicolumn{3}{|c|}{ Private sector (\%) } \\
\hline & $\begin{array}{r}2010 \\
(n=2066)\end{array}$ & $\begin{array}{r}2013 \\
(n=2182)\end{array}$ & $\begin{array}{r}\text { Percentage } \\
\text { point increase }\end{array}$ & $\begin{array}{r}2010 \\
(n=2362)\end{array}$ & $\begin{array}{r}2013 \\
(n=2581)\end{array}$ & $\%$ increase & $\begin{array}{r}2010 \\
(n=1056)\end{array}$ & $\begin{array}{r}2013 \\
(n=801)\end{array}$ & $\begin{array}{r}\text { Percentage } \\
\text { point increase }\end{array}$ \\
\hline 1 & 72.0 & 81.0 & 9.0 & 72.5 & 79.1 & 6.6 & 67.0 & 72.4 & 5.4 \\
\hline 2 & 51.3 & 67.7 & 16.4 & 55.4 & 66.3 & 10.9 & 42.0 & 53.7 & 11.7 \\
\hline 3 & 39.3 & 57.8 & 18.5 & 47.2 & 56.9 & 9.7 & 30.1 & 43.6 & 13.5 \\
\hline 4 & 31.2 & 48.9 & 17.7 & 41.5 & 51.5 & 10.0 & 24.0 & 35.3 & 11.3 \\
\hline 5 & 24.9 & 42.3 & 17.4 & 38.3 & 47.0 & 8.7 & 20.5 & 30.3 & 9.8 \\
\hline 6 & 24.9 & 40.4 & 15.5 & 36.7 & 45.5 & 8.8 & 17.9 & 28.7 & 10.8 \\
\hline
\end{tabular}

Table 6. Comparing exclusive breastfeeding practice between mothers employed by the government and nonworking mothers, with consideration of paid maternity leave duration

\begin{tabular}{|c|c|c|c|c|c|c|c|c|}
\hline \multirow{3}{*}{$\begin{array}{l}\text { Infant age } \\
\text { (months) }\end{array}$} & \multicolumn{4}{|c|}{2010 (\%) } & \multicolumn{4}{|c|}{$2013(\%)$} \\
\hline & PML status $^{\dagger}$ & $\begin{array}{r}\text { Government } \\
(n=2066)\end{array}$ & $\begin{array}{r}\text { Nonworking } \\
(n=2362)\end{array}$ & $\begin{array}{l}\text { Percentage } \\
\text { point difference }\end{array}$ & PML status $^{\ddagger}$ & $\begin{array}{r}\text { Government } \\
(\mathrm{n}=\mathbf{2 1 8 2})\end{array}$ & $\begin{array}{r}\text { Nonworking } \\
(n=2581)\end{array}$ & $\begin{array}{r}\text { Percentage } \\
\text { point difference }\end{array}$ \\
\hline & & $A$ & B & $(B-A)$ & & $A$ & B & $(B-A)$ \\
\hline 1 & Active & 72.0 & 72.5 & 0.5 & Active & 81.0 & 79.1 & -1.9 \\
\hline 2 & $1 / 2$ Active & 51.3 & 55.4 & 4.1 & Active & 67.7 & 66.3 & -1.4 \\
\hline 3 & Inactive & 39.3 & 47.2 & 7.9 & Active & 57.8 & 56.9 & -0.9 \\
\hline 4 & Inactive & 31.2 & 41.5 & 10.3 & Inactive & 48.9 & 51.5 & +2.6 \\
\hline 5 & Inactive & 24.9 & 38.3 & 13.4 & Inactive & 42.3 & 47.0 & +4.7 \\
\hline 6 & Inactive & 24.9 & 36.7 & 11.8 & Inactive & 40.4 & 45.5 & +5.1 \\
\hline
\end{tabular}

†Paid maternity leave (PML) duration of 56 days, taken 2 weeks before the expected delivery date ( 42 days of active PML, postpartum); ${ }^{*} P M L$ duration of 105 days, taken 2 weeks before the expected delivery date (91 days of active PML, postpartum); Active ( 30 days of active PML); $1 / 2$ Active (12 days active PML); Inactive (PML terminated); +In favor of nonworking mothers. 
mothers $(48.9 \%)$ by 2.6 percentage points. This trend continued until 6 months of infant age, when the EBF prevalence for nonworking mothers $(45.5 \%)$ was greater than that for government-employed mothers $(40.4 \%)$ by 5.1 percentage points. Although nonworking mothers practiced $\mathrm{EBF}$ at 6 months of infant age more than government-employed mothers for both years 2010 and 2013, the difference was smaller in 2013 (5.1 percentage points) than it was in 2010 (11.8 percentage points), as presented in Table 6.

Using multiple logistic regression models for EBF at 6 months of infant age, mothers employed by the government were $45 \%$ less likely to practice EBF in 2010 (AoR 0.55 ; 95\% CI 0.48 to $0.63 ; P<0.001$ ) and $19 \%$ less likely to practice EBF in 2013 (AoR $0.81 ; 95 \%$ CI 0.72 to $0.91 ; P<0.001$ ) compared with nonworking mothers, showing a significant improvement. Mothers employed in the private sector were $60 \%$ less likely to practice EBF in 2010 (AoR 0.40; $95 \%$ CI 0.33 to 0.47; $P<0.001$ ) and $52 \%$ less likely to practice EBF in 2013 (AoR 4.8 ; $95 \%$ CI 0.41 to $0.58 ; P<0.001)$ compared with nonworking mothers, indicating a modest improvement (Table 4).

\section{Discussion}

The prevalence of EBF in Brunei increased significantly in 2013 compared with the prevalence in 2010. The prevalence of EBF at 6 months in Brunei (41\%) in 2013 was consistent with the average prevalence in Asia in 2010 (41\%) [13] and higher than that for many other high-income countries [14]. For example, EBF at 6 months of infant age was $18.8 \%$ in the USA [15]; $1 \%$ in the UK [16]; and $11 \%$ in Thailand [17]. EBF of infants aged $<6$ months in Malaysia was $14.5 \%$ in 2006 [18]. Globally, the rates of EBF at 6 months of infant age generally were considered "unsatisfactory" [14], because only two-fifths of infants get exclusively breastfed in their first 6 months of life [6].

The present study showed that multiparous mothers in Brunei practiced EBF more than primiparous mothers, consistent with a cross-sectional study in the United Arab Emirates that found an almost 2-fold-higher prevalence of breastfeeding initiation by multiparous mothers $(P<0.001)[19]$. In a Canadian study, there was a 2-fold-higher likelihood of EBF practice at 6 months by multiparous mothers, attributed to the experience of breastfeeding the previous child or children by multiparous mothers [20].

In our present study, we found that the prevalence of EBF among mothers of Malay ethnicity was greater than for mothers of other ethnicities. This contradicts the findings of a study conducted in Singapore that reported a greater prevalence of EBF among Chinese mothers at 2 months of infant age than among Malay mothers, but less than that among Indian mothers [21]. A study in the USA found that non-Hispanic white infants were more likely to "have ever been breastfed" than non-Hispanic black infants, although the difference in odds was not different [22]. Other studies too, have found an influence of race, culture, ethnicity, and environment on breastfeeding practices $[9,23,24]$. Our present study showed that maternal district of residence had no significant influence on EBF. By contrast, studies conducted in Bangladesh [9], Germany [25], and Tanzania [26] reported a significant influence of geographical location on EBF practice.

Contrary to our findings of a greater likelihood of EBF for female infants, a study in Alberta found that more male infants were exclusively breastfed than female infants, although the difference was not significant [20]. Nevertheless, our present finding of male infants being exclusively breastfed less than female infants was similar to that found by a study in Singapore [21].

EBF practice disaggregated by maternal employment showed that the practice by working mothers still lagged behind that by nonworking mothers. However, the EBF prevalence among government-employed mothers in 2013 was found to be higher than that for nonworking mothers during the first 3 months postpartum, during active PML. However, the prevalence diminished once the mothers returned to work. Our present study found that there was increased EBF practice among mothers employed by the government when the PML is fully active. Similarly, a study that investigated the paid parental leave (PPL) in Australia, drawing a sample from 2 prevalence surveys, observed better physical and mental health and well-being, in mothers during the post-PPL era, although the "effects were small" [27]. Another study that investigated the effects of Germany's Elterngeld (new parental leave benefits) 2007 policy on breastfeeding practices in Germany found that breastfeeding duration increased by $9.2 \%$ at 4 months and $7.9 \%$ at 6 months of infant age, respectively, among the beneficiaries of the parental leave reforms [25]. A systematic review of the literature with participants from Australia, Canada, Lebanon, Norway, Sweden, and the USA concluded that PML has health benefits, with longer paid leaves conferring higher impact [28]. PML not only improves breastfeeding rates and child-parent bonding, but it also offers health and well-being benefits to the mother and addresses inequalities by reducing the "time-income trade-off" for new mothers and their families during the infant nursing period [27].

Generally, the EBF prevalence in Brunei was still lower than the World Health Assembly target of at least 50\% EBF prevalence among new mothers [29]. The main strength of this study was the use of large data sets of EBF status, drawn from the national $\mathrm{MCH}$ databases, while a limitation was the exclusion of certain variables reported to influence 
breastfeeding practice (such as maternal income, smoking status, and educational attainment) because of incomplete data for such variables. Promoting EBF practice, such as by the use of social media and religious platforms, and women-friendly work policies - such as protected time in the workplace for breastmilk expression, flexible hours, and avoidance of night shifts in the first 3 months after returning to work; and provision of breastfeeding rooms in the workplace - may improve EBF prevalence and these aspects warrant further investigation.

\section{Conclusion}

Strategies for promoting EBF practice, such as paid paternity leave, moderately increased the prevalence of EBF among beneficiaries. A similar increase was not seen among nonworking mothers.

Author contributions. All authors contributed substantially to the conception and design of the study. NAAT, MMA, and SR acquired the data and all authors substantially contributed to its analysis and interpretation. NAAT and MMA drafted the manuscript and SR and AK critically revised it. All authors approved the final version submitted for publication and take responsibility for the statements made in the published article.

Acknowledgments. The authors appreciate the support provided by the $\mathrm{MCH}$ staff for making available the data needed for this study. We did not receive any specific grant for this research from any funding agency in the public, commercial, or not-for-profit sectors.

Conflict of interest statement. The authors have each completed and submitted an International Committee of Medical Journal Editors Uniform Disclosure Form for Potential Conflicts of Interest. None of the authors discloses any conflict of interest.

\section{References}

[1] World Health Organization. WHO exclusive breastfeeding [Internet]. 2017 [cited 2017 Apr 28]. Available from: http://www.who.int/ nutrition/topics/exclusive_breastfeeding/en/.

[2] William BC, Kyung LM. Exclusive breastfeeding for six months: the WHO six months recommendation in the Asia Pacific Region. Asia Pac J Clin Nutr. 2014; 23:344-50.

[3] Rosser J. Optimal duration of exclusive breastfeeding. Practising Midwife. 2002; 5:30-1.
[4] Kramer MS, Chalmers B, Hodnett ED, Sevkovskaya Z, Dzikovich I, Shapiro S, et al. Promotion of Breastfeeding Intervention Trial (PROBIT): a randomized trial in the Republic of Belarus. JAMA. 2001; 285:413-20.

[5] Weimer JP. The economic benefits of breastfeeding: a review and analysis. Food Assistance and Nutrition Research Reports No. 13, United States Department of Agriculture, Economic Research Service. Washington, DC: USDA; 2001.

[6] UNICEF. From the first hour of life making the case for improved infant and young child feeding everywhere key findings 2016 Indicators Recommended Practices [Internet]. 2016 [cited 2017 Apr 28]. Available from: https://data.unicef.org/wp-content/ uploads/2016/10/From-the-first-hour-key-findings2016-for-web.pdf

[7] Ogbuanu C, Glover S, Probst J, Liu J, Hussey J. The effect of maternity leave length and time of return to work on breastfeeding. Pediatrics. 2011; 127:e1414-27.

[8] Cooklin AR, Donath SM, Amir LH. Maternal employment and breastfeeding: results from the longitudinal study of Australian children. Acta Paediatr. 2008; 97:620-3.

[9] Mihrshahi S, Kabir I, Roy SK, Agho KE, Senarath U, Dibley MJ; South Asia Infant Feeding Research Network (SAIFRN). Determinants of infant and young child feeding practices in Bangladesh: secondary data analysis of demographic and health survey 2004. Food Nutr Bull. 2010; 31:295-313.

[10] Wang W, Lau Y, Chow A, Chan KS. Breast-feeding intention, initiation and duration among Hong Kong Chinese women: a prospective longitudinal study. Midwifery. 2014; 30:678-87.

[11] Hawkins SS, Griffiths LJ, Dezateux C, Law C. The impact of maternal employment on breast-feeding duration in the UK Millennium Cohort Study. Public Health Nutr. 2007; 10:891-6.

[12] International Labour Organization. Maternity and paternity at work, Law and Practice Across the World [Internet]. Geneva, Switzerland ILO; 2014 [cited 2017 Apr 28]. Available from: http://www.ilo. org/wcmsp5/groups/public/ - -dgreports/ - -dcomm/documents/ publication/wcms_242617.pdf

[13] Cai X, Wardlaw T, Brown DW. Global trends in exclusive breastfeeding. Int Breastfeed J. 2012; 7:12. doi: 10.1186/1746-4358-7-12

[14] Victora CG, Bahl R, Barros AJD, França GVA, Horton S, Krasevec J, et al. Breastfeeding in the 21st century: Epidemiology, mechanisms, and lifelong effect. Lancet. 2016; 387:475-90.

[15] Centers for Disease Control and Prevention. Breastfeeding Report Card: United States, 2014 [Internet]. Atlanta: CDCP; 2014 [cited 2017 Apr 28]. Available from: https://www.cdc.gov/breastfeeding/ pdf/2014breastfeedingreportcard.pdf

[16] National Health Service. United Kingdom Infant Feeding Survey 2010 [Internet]. 2010 [cited 2017 Apr 28]. Available from: $h t t p s: / /$ data.gov.uk/dataset/infant-feeding-survey-2010/resource/6e91499a4174-4ede-9207-b99d361f0ee6

[17] Laisiriruangrai P, Wiriyasirivaj B, Phaloprakarn C, Manusirivithaya S. Prevalence of exclusive breastfeeding at 3, 4 and 6 months in Bangkok Metropolitan Administration Medical College and Vajira Hospital. J Med Assoc Thai. 2008; 91:962-7.

[18] Fatimah S, Siti Saadiah HN, Tahir A, Hussain Imam MI, Ahmad Faudzi Y. Breastfeeding in Malaysia: Results of the Third National Health and Morbidity Survey (NHMS III) 2006. Malays J Nutr. 2010; 16:195-206.

[19] Radwan H. Patterns and determinants of breastfeeding and complementary feeding practices of Emirati Mothers in the United Arab Emirates. BMC Public Health. 2013; 13:171. doi: 10.1186/1471-245813-171 


\section{A ASIAN

[20] Jessri M, Farmer AP, Maximova K, Willows ND, Bell RC. Predictors of exclusive breastfeeding: observations from the Alberta pregnancy outcomes and nutrition (APrON) study. 2013; 13:77. doi: 10.1186/1471-2431-13-77

[21] Foo LL, Quek SJS, Ng SA, Lim MT, Deurenberg-Yap M. Breastfeeding prevalence and practices among Singaporean Chinese, Malay and Indian mothers. Health Promot Int. 2005; 20:229-7.

[22] Jones JR, Kogan MD, Singh GK, Dee DL, Grummer-Strawn LM. Factors associated with exclusive breastfeeding in the United States. Pediatrics. 2011; 128:1117-25.

[23] Jayachandran S, Kuziemko I. Why do mothers breastfeed girls less than boys? Evidence and implications for child health in India. Q J Econ. 2011; 126:1485-538.

[24] Alhaji MM, Sharbawi R, Majeed, Tuah NAA. Sociodemographic factors associated with uptake of exclusive breastfeeding practice in Brunei Darussalam. Brunei Int Med J. 2017; 13:12-9.
[25] Kottwitz A, Oppermann A, Spiess CK. Parental leave benefits and breastfeeding in Germany: effects of the 2007 reform. Rev Econ Household. 2016; 14:859-90.

[26] Nkala T, Msuya S. Prevalence and predictors of exclusive breastfeeding among women in Kigoma region, Western Tanzania: a community based cross-sectional study. Int Breastfeed J. 2011; 6:17. doi: 10.1186/1746-4358-6-17

[27] Hewitt B, Strazdins L, Martin B. The benefits of paid maternity leave for mothers' post-partum health and wellbeing: evidence from an Australian evaluation. Soc Sci Med. 2017; 182:97-105.

[28] Aitken Z, Garrett CC, Hewitt B, Keogh L, Hocking JS, Kavanagh AM. The maternal health outcomes of paid maternity leave: a systematic review. Soc Sci Med. 2015; 130:32-41.

[29] World Health Organization. Essential nutrition action, improving maternal, newborn, infant and young child health and nutrition [Internet]. Geneva: WHO; 2013 [cited 2017 Apr 28]. Available from: http://apps.who.int/iris/bitstream/10665/84409/1/9789241505550_eng.pdf 